\title{
Transcirculation Pipeline embolization device deployment: a rescue technique
}

\author{
Edison P. Valle-Giler, MD, Elias Atallah, MD, Stavropoula Tjoumakaris, MD, \\ Robert H. Rosenwasser, MD, and Pascal Jabbour, MD \\ Department of Neurological Surgery, Thomas Jefferson University and Jefferson Hospital for Neuroscience, Philadelphia, \\ Pennsylvania
}

The Pipeline embolization device (PED) has become a very important tool in the treatment of nonruptured cerebral aneurysms. However, a patient's difficult anatomy or vascular stenosis may affect the device delivery. The purpose of this article was to describe an alternate technique for PED deployment when ipsilateral anatomy is not amenable for catheter navigation.

A 44-year-old woman with a symptomatic 6-mm right superior hypophyseal artery aneurysm and a known history of right internal carotid artery dissection presented for PED treatment of her aneurysm. An angiogram showed persistence of the arterial dissection with luminal stenosis after 6 months of dual antiplatelet treatment. The contralateral internal carotid artery was catheterized and the PED was deployed via a transcirculation approach, using the anterior communicating artery. Transcirculation deployment of a PED is a viable option when ipsilateral anatomy is difficult or contraindicated for this treatment.

https://thejns.org/doi/abs/10.3171/2017.2.FOCUS16485

KEY WORDS transcirculation; contralateral internal carotid artery; Pipeline embolization device; rescue technique

$\mathrm{T}$

HE Pipeline embolization device (PED) has changed the paradigm of aneurysm treatment since it was approved in $2011.5,13,18$ The popularity of the PED is based on its efficacy in treating aneurysms when compared with conventional coiling (> 80\% vs $66 \%$ aneurysm obliteration rate, respectively, with minimal-if any-aneurysm recurrence). ${ }^{2,3,5,6,10,13,15}$

Usually the PED deployment is anterograde, with the delivery microcatheter entering the inflow of the aneurysm. Sometimes the deployment can be difficult, mainly because of tortuous anatomy, predisposing patients to complications like device migration and malpositioning, aneurysm rupture, delayed thrombosis, and stroke., ${ }^{4,9}$

We present a case of transcirculation PED deployment in a patient with right internal carotid artery (ICA) dissection. This technique can be extrapolated to patients with difficult ipsilateral ICA anatomy, diseased ipsilateral ICA (dissections, fibromuscular dysplasia), or any other cause that contraindicates ipsilateral circulation deployment.

\section{Case Report}

History and Examination

We present the case of a 44-year-old woman who, upon workup for worsening headaches, was found to have a right superior hypophyseal artery aneurysm and a family history of ruptured brain aneurysms. The patient underwent digital subtraction angiography that was complicated with ipsilateral right ICA dissection just above the bifurcation. On further evaluation, the dissection flap was nonflow limiting, and the patient had a complete circle of Willis. The patient was treated conservatively with immediate

ABBREVIATIONS ACA = anterior cerebral artery; $A C O A=$ anterior communicating artery; $C C A=$ common carotid artery; $I C A=$ internal carotid artery; $P E D=$ Pipeline embolization device.

SUBMITTED November 8, 2016. ACCEPTED February 22, 2017.

INCLUDE WHEN CITING DOI: 10.3171/2017.2.FOCUS16485. 


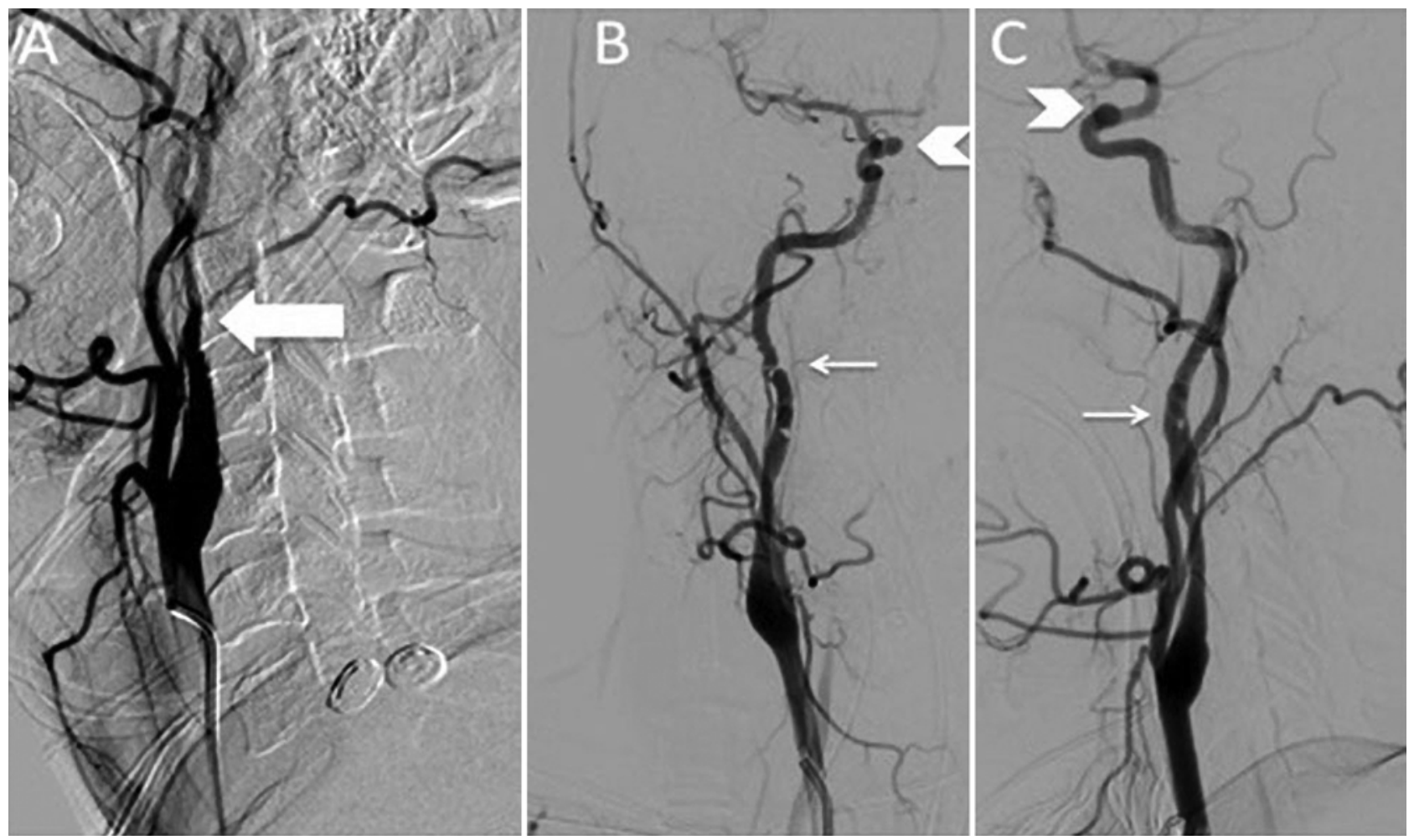

FIG. 1. Angiogram showing a lateral view of the right ICA dissection (A); notice the tapering of the ICA above the bifurcation (thick arrow). An anteroposterior view (B) and a lateral view (C) of the 6-month follow-up digital subtraction angiography. Severe ICA stenosis is noted where the previous dissection happened (thin arrows). The superior hypophyseal aneurysm is shown in panels $B$ and C (arrowheads).

heparinization and $75 \mathrm{mg} / \mathrm{day}$ of clopidogrel plus $81 \mathrm{mg} /$ day of aspirin for 6 months. The patient was followed up 6 months later with CT angiography that showed improvement of the dissection. At this point, she was scheduled for elective PED treatment of the aneurysm.

\section{Technical Procedure}

On treatment day, the P2Y12 assay was checked to confirm correct platelet inhibition (P2Y12 reaction unit [PRU] 142 , baseline $280,49 \%$ inhibited). The right common carotid artery (CCA) injection showed persistent residual stenosis (Fig. 1), making the ipsilateral PED deployment challenging. The left ICA injection showed a functional

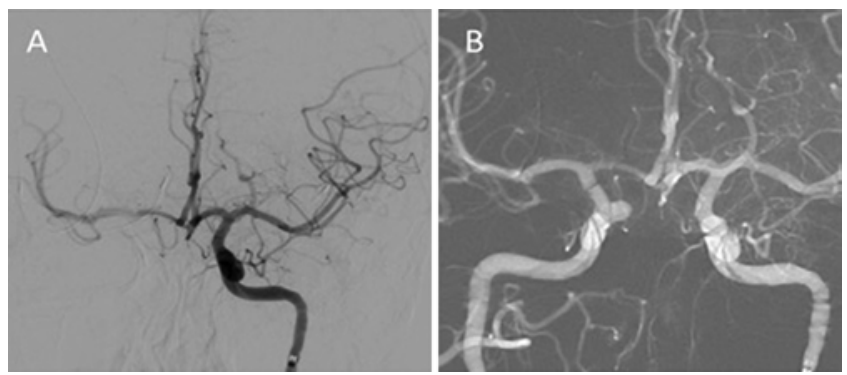

FIG. 2. A: Left ICA injection angiogram showing cross-flow to the right ICA circulations and a functional ACoA complex. B: Roadmap angiogram of both circulations was used to navigate the Marksman catheter past the right superior hypophyseal aneurysm. anterior communicating artery $(\mathrm{ACoA})$ complex and generous cross-filling into the right ICA circulation (Fig. 2).

At this point, a second groin sheath was placed and the patient underwent heparinization with the usual protocol for Pipeline deployment (5000 IU of heparin to achieve the activated clotting time goal of 2-3 times the baseline). A 6-Fr envoy catheter was positioned at the right CCA. A Penumbra Neuron Max was brought up to the left CCA bifurcation, and then the Navien 0.058-inch catheter (Medtronic, Inc.) was brought up to the left petrous ICA. A roadmap angiographic run was obtained (Fig. 2) and a 0.027-inch Marksman catheter (Medtronic, Inc.) along with the Synchro2 guidewire (Stryker Neurovascular) was navigated to the left anterior cerebral artery (ACA), $\mathrm{ACoA}$, contralateral right $\mathrm{ACA}$, and right ICA, and was placed at the distal petrous segment of the right (contralateral) ICA. At this point, the left ICA Navien catheter was advanced to the distal ICA segment to provide better catheter support. A classic PED model was brought up to the tip of the Marksman catheter (Fig. 3). The PED was deployed at that position. ${ }^{14}$ An angiographic run showed good wall apposition, the distal PED coil and pusher wire were retrieved without problems, and the entire delivery system was removed (Fig. 4).

\section{Posttreatment Outcome}

There were no complications during the procedure, and the patient was discharged home on postoperative Day 1 in stable condition. 

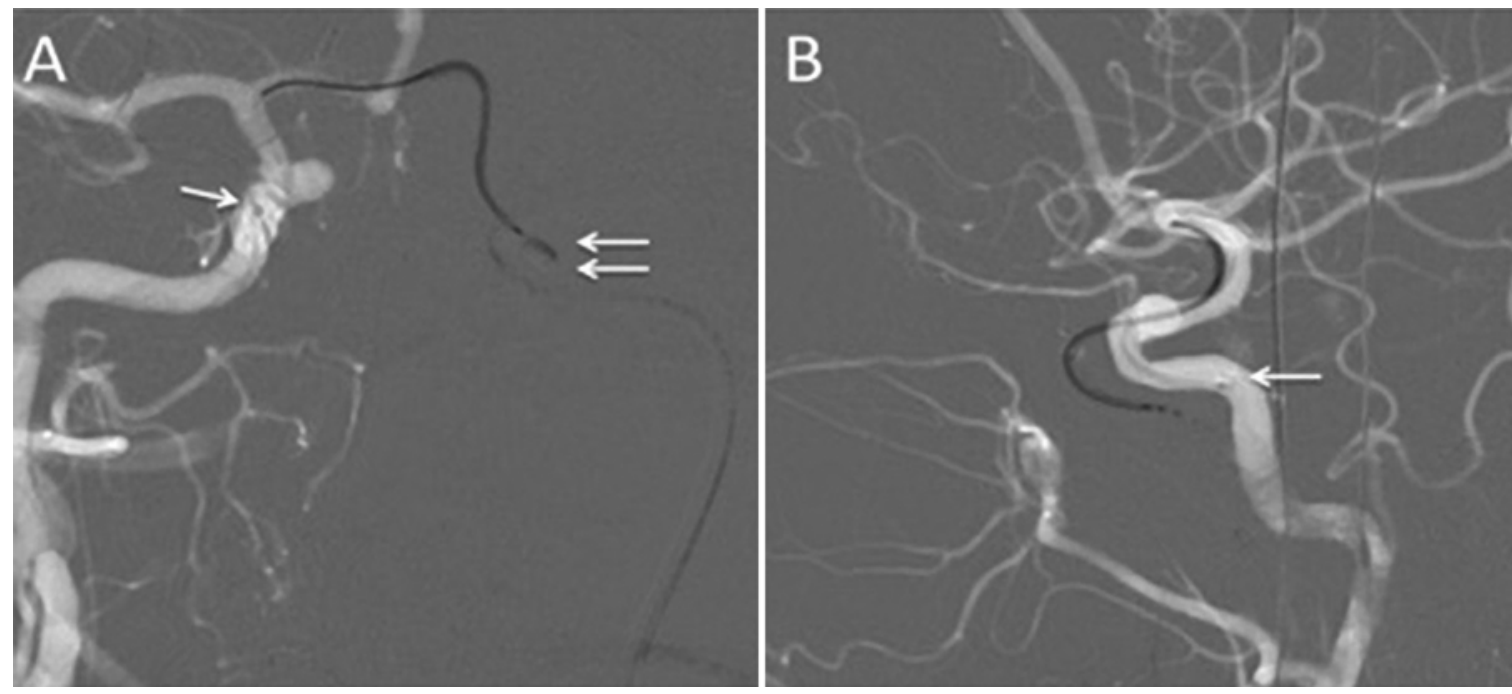

FIG. 3. Anteroposterior (A) and lateral (B) roadmap angiograms of the right ICA circulation. The Navien 0.58-inch catheter had initially been placed on the cavernous left ICA (double arrows). The 0.27 -inch Marksman catheter was navigated to the right proximal ICA cavernous segment, past the aneurysm (single arrows). The PED is being navigated through the Marksman catheter into the right $A_{1}$ artery. The Navien catheter positioned on the left distal petrous ICA segment (double arrows) will be advanced to the distal left ICA segment prior to PED deployment to provide better catheter support and to avoid PED malpositioning during deployment.

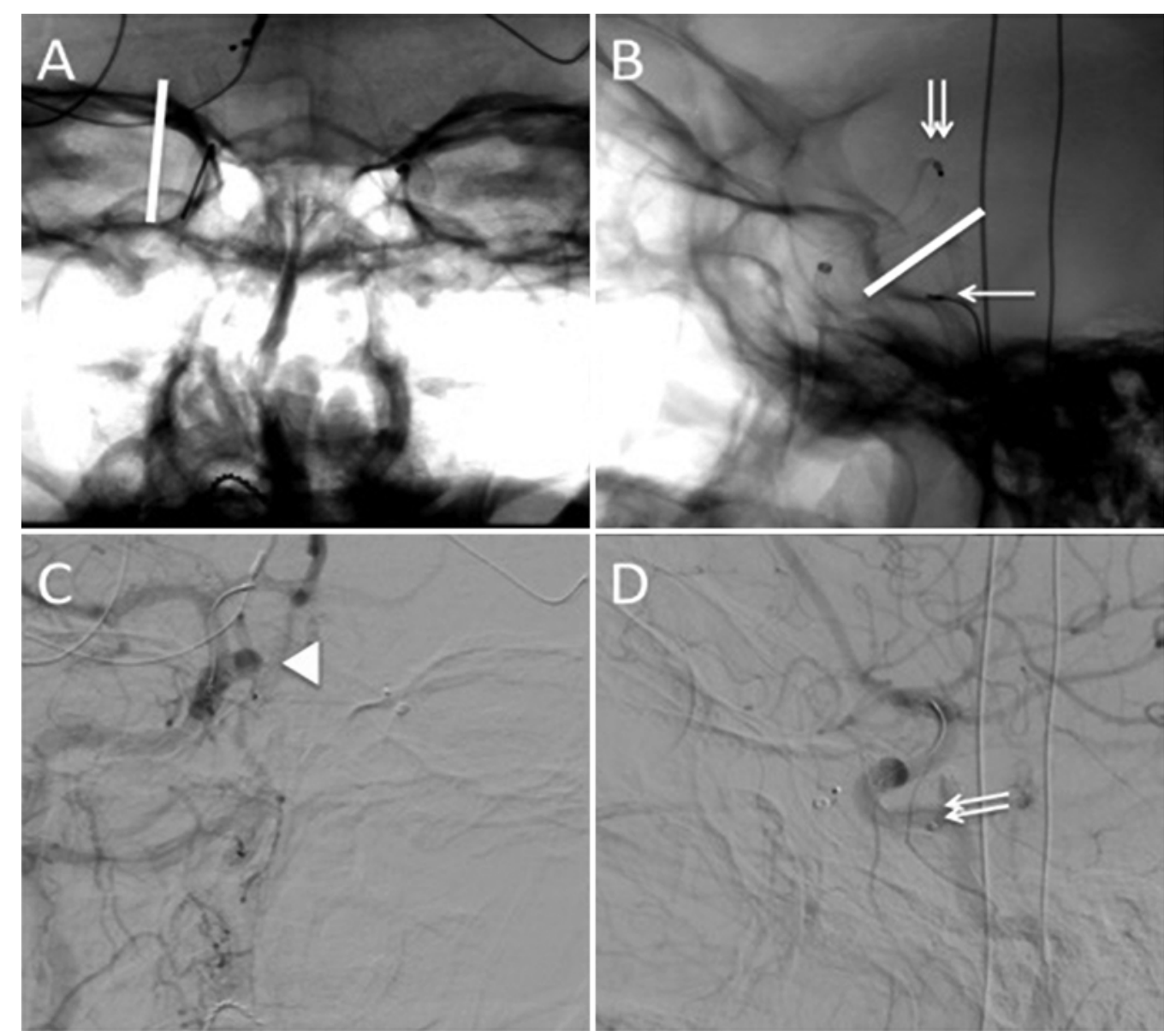

FIG. 4. A and B: Anteroposterior and lateral views of the PED braid deployed (straight lines in panels A and B), with the distal tip of the Marksman at the left $A_{1}$ segment, proximal to the braid (double arrows in panel $B$ ) and the distal PED pusher wire and coil distal to the aneurysm and the braid, in the left cavernous ICA segment (single arrow in panel B). C and D: Late arterial phase with the staggering of contrast in the right superior hypophyseal segment aneurysm (arrowhead in panel C, double arrows in panel D). 


\section{Discussion}

Pipeline embolization device deployment can sometimes be difficult, especially when encountering tortuous anatomy. We describe a case in which ipsilateral deployment was not possible due to arterial dissection and stenosis. After evaluating the patency of the circle of Willis, we decided to approach the contralateral side (left ICA circulation) to achieve transcirculation PED deployment (on the right ICA). This is the first known description of this approach as a rescue technique for deployment of PED.

Transcirculation techniques are reserved for the treatment of complex cerebral aneurysms, and they should be reserved for patients in whom the risks of leaving their aneurysms untreated are high and who have a strong family history of ruptured aneurysms. ${ }^{1}$ These techniques can be achieved via a communicating vessel, and they are especially efficacious when the angulation of the parent or branching vessel would be difficult or impossible to catheterize from an antegrade approach. $1,8,11,12,16,17,19,20$

Transcirculation techniques for treatment of intracranial aneurysms have been extensively described for intrasaccular coiling, but not for extrasaccular flow diversion treatment. $1,7,8,11,12,16,17,19,20$ They are associated with increased risk of thromboembolic complications due to navigation of smaller communicating cerebral arteries with the microcatheters, ${ }^{1}$ and these procedures should only be attempted after careful evaluation of the anatomy, when the ipsilateral parent vessel approach is difficult or contraindicated.

There are several factors to be considered before attempting transcirculation techniques, and they are as follows.

1) Bilateral femoral access is necessary for correct navigation of the catheters. A dual road map should be obtained for proper catheter navigation (Fig. 2). Sometimes, when it is difficult to visualize the ACoA complex, counter-compression of the ICA may be necessary for proper visualization.

2) The caliber of the communicating artery should allow the passage of the delivery catheter. A diameter of 1 $\mathrm{mm}$ is usually enough to pass the delivery catheter $(0.93 \mathrm{~mm})$. When the surgeon is having problems passing the catheter through the ACoA complex, a quick intraarterial infusion of nicardipine could be used to relax and dilate the complex. ${ }^{11,16}$

3) The size of the ICA of interest should be carefully measured to calculate the size and length of the PED. Deploying a longer-than-needed PED from a transcirculation approach would translate into braid coverage of distal circulation and small perforator arteries, increasing the risk of ischemic strokes. Deploying a shorter PED translates into insufficient distal coverage with possible distal braid retraction and herniation into the aneurysm sac, creating flow diversion into the aneurysm dome (increased risk of aneurysm rupture). We recommend measuring in 3D views as well as conventional high-magnification views to average the measurements and choose the braid.

4) Catheter support is essential every time a transcirculation approach is planned. A shuttle catheter should be brought to the ICA bifurcation. The distal access catheter (Navien 0.058-inch catheter; Medtronic, Inc.) should be carried as distal as possible to avoid problems with trackability of the PED. The entire system should be unloaded (pulling the catheters to straighten them up) prior to the initial PED deployment to avoid malpositioning of the braid.

5) Placement of a single PED should be the goal to prevent thromboembolic complications from longer procedure times. In theory, the newer Pipeline Flex could offer an advantage over the classic model due to its improved flexibility with catheter navigation and its ability to resheath when deployment is not optimal. This last statement would depend on the operator. We decided to use the classic model because we are more comfortable with it.

\section{Conclusions}

Transcirculation PED deployment is a good option when encountering difficult or contraindicated catheter navigation in the ipsilateral circulation. Although this technique may potentially increase the incidence of thromboembolic complications, it is safe and efficacious when compared with the natural history of untreated aneurysms, especially in younger individuals with a strong family history of ruptured brain aneurysms. We recommend optimal P2Y12 inhibition and heparinization for the patient at the beginning of the procedure, with activated clotting time follow-up.

\section{References}

1. Albuquerque FC, Gonzalez LF, Hu YC, Newman CB, McDougall CG: Transcirculation endovascular treatment of complex cerebral aneurysms: technical considerations and preliminary results. Neurosurgery 68:820-830, 2011

2. Becske T, Kallmes DF, Saatci I, McDougall CG, Szikora I, Lanzino G, et al: Pipeline for uncoilable or failed aneurysms: results from a multicenter clinical trial. Radiology 267:858868,2013

3. Chalouhi N, Tjoumakaris S, Starke RM, Gonzalez LF, Randazzo C, Hasan D, et al: Comparison of flow diversion and coiling in large unruptured intracranial saccular aneurysms. Stroke 44:2150-2154, 2013

4. Chitale R, Gonzalez LF, Randazzo C, Dumont AS, Tjoumakaris S, Rosenwasser R, et al: Single center experience with Pipeline stent: feasibility, technique, and complications. Neurosurgery 71:679-691, 2012

5. Fiorella D, Lylyk P, Szikora I, Kelly ME, Albuquerque FC, McDougall CG, et al: Curative cerebrovascular reconstruction with the Pipeline Embolization Device: the emergence of definitive endovascular therapy for intracranial aneurysms. J Neurointerv Surg 1:56-65, 2009

6. Fischer S, Vajda Z, Aguilar Perez M, Schmid E, Hopf N, Bäzner H, et al: Pipeline Embolization Device (PED) for neurovascular reconstruction: initial experience in the treatment of 101 intracranial aneurysms and dissections. Neuroradiology 54:369-382, 2012

7. Gurian JH, Viñuela F, Gobin YP, Waston VE, Duckwiler GR, Gulielmi G: Aneurysm rupture after parent vessel sacrifice: treatment with Guglielmi detachable coil embolization via retrograde catheterization: case report. Neurosurgery 37:1216-1221, 1995

8. Heye S, Stracke CP, Nordmeyer H, Heddier M, Stauder M, Chapot R: Retrograde access to the posterior inferior cerebellar artery in balloon-assisted coiling of posterior inferior 
cerebellar artery aneurysms. J Neurointerv Surg 7:824828,2015

9. Jabbour P, Chalouhi N, Tjoumakaris S, Gonzalez LF, Dumont AS, Randazzo C, et al: The Pipeline Embolization Device: learning curve and predictors of complications and aneurysm obliteration. Neurosurgery 73:113-120, 2013

10. Kallmes DF, Hanel R, Lopes D, Boccardi E, Bonafé A, Cekirge S, et al: International retrospective study of the Pipeline Embolization Device: a multicenter aneurysm treatment study. AJNR Am J Neuroradiol 36:108-115, 2015

11. Kim YJ, Ho Ko J: Coiling of a recurrent broad-necked posterior communicating aneurysm incorporating a fetal cerebral artery: a technical case report. Interv Neuroradiol 21:4449, 2015

12. Lubicz B, Bruneau M, Dewindt A, Lefranc F, Balériaux D, De Witte O: Endovascular treatment of proximal anterior cerebral artery aneurysms. Neuroradiology 51:99-102, 2009

13. Lylyk P, Miranda C, Ceratto R, Ferrario A, Scrivano E, Luna HR, et al: Curative endovascular reconstruction of cerebral aneurysms with the Pipeline Embolization Device: the Buenos Aires experience. Neurosurgery 64:632-633, N636, 2009

14. Ma D, Xiang J, Choi H, Dumont TM, Natarajan SK, Siddiqui $\mathrm{AH}$, et al: Enhanced aneurysmal flow diversion using a dynamic push-pull technique: an experimental and modeling study. AJNR Am J Neuroradiol 35:1779-1785, 2014

15. Molyneux AJ, Kerr RSC, Yu LM, Clarke M, Sneade M, Yarnold JA, et al: International subarachnoid aneurysm trial (ISAT) of neurosurgical clipping versus endovascular coiling in 2143 patients with ruptured intracranial aneurysms: a randomised comparison of effects on survival, dependency, seizures, rebleeding, subgroups, and aneurysm occlusion. Lancet 366:809-817, 2005

16. Moret J, Ross IB, Weill A, Piotin M: The retrograde approach: a consideration for the endovascular treatment of aneurysms. AJNR Am J Neuroradiol 21:262-268, 2000

17. Navarro R, Yoon J, Dixon T, Miller DA, Hanel RA, Tawk RG: Retrograde trans-anterior communicating artery rescue of unopened Pipeline Embolization Device with balloon di- lation: complication management. J Neurointerv Surg 7:e7, 2015

18. Nelson PK, Lylyk P, Szikora I, Wetzel SG, Wanke I, Fiorella D: The Pipeline Embolization Device for the intracranial treatment of aneurysms trial. AJNR Am J Neuroradiol 32:34-40, 2011

19. Nossek E, Chalif DJ, Levine M, Setton A: Modifying flow in the ACA-ACoA complex: endovascular treatment option for wide-neck internal carotid artery bifurcation aneurysms. J Neurointerv Surg 7:351-356, 2015

20. Puri AS, Erdem E: Unusual intracranial stent navigation through the circle of Willis in a patient with recurrent basilar tip aneurysm during stent-assisted coiling. A case report. Interv Neuroradiol 15:81-86, 2009

\section{Disclosures}

Drs. Jabbour and Tjoumakaris are consultants for Medtronic, Inc.

\section{Author Contributions}

Conception and design: Jabbour, Tjoumakaris. Acquisition of data: Valle-Giler, Atallah. Analysis and interpretation of data: Jabbour, Valle-Giler, Atallah, Tjoumakaris. Drafting the article: Valle-Giler, Atallah. Critically revising the article: all authors. Reviewed submitted version of manuscript: Tjoumakaris. Approved the final version of the manuscript on behalf of all authors: Jabbour. Study supervision: Jabbour, Rosenwasser.

\section{Supplemental Information}

\section{Current Affiliations}

Dr. Valle-Giler: Department of Neurosurgery, Ochsner Health Care System, New Orleans, LA.

\section{Correspondence}

Pascal Jabbour, Department of Neurological Surgery, Thomas Jefferson University Hospital, 909 Walnut St., 3rd Fl., Philadelphia, PA 19107. email: pascal.jabbour@jefferson.edu. 